\title{
Ultrasound-guided biopsy of osteolytic metastasis - could be less than three cores enough?
}

\author{
Romeo Ioan Chira ${ }^{1,2}$, Alexandra Chira ${ }^{3}$, Adriana Calauz ${ }^{4}$, Roberta Maria Manzat-Saplacan ${ }^{1,2}$, \\ Georgiana Nagy ${ }^{1,2}$, Petru Adrian Mircea1, Simona Valean ${ }^{1,2}$
}

${ }^{1} 1$ stInternal Medicine Department, "Iuliu Hatieganu" University of Medicine and Pharmacy, ${ }^{2}$ Gastroenterology Department, Emergency Clinical County Hospital, ${ }^{3}{ }^{\text {nd }}$ Internal Medicine Department, "Iuliu Hatieganu" University of Medicine and Pharmacy, "“"Leon Daniello" Pneumophthisiology Clinical Hospital, Cluj-Napoca, Romania

\begin{abstract}
Aims: The purpose of this study was to analyze the diagnostic yield and accuracy of the ultrasound (US) guided core biopsy in a population of patients with osteolytic metastasis. Materials and methods: We performed a retrospective analysis of 16 consecutive cases of US-guided core biopsies of osteolytic lesions performed in our Ultrasound Unit, from January 2006 to May 2017. We used $18 \mathrm{G}$ or $16 \mathrm{G}$ Tru-cut needles coupled with automated biopsy guns. We procured a maximum number of two tissue specimens per patient. Results: We obtained a diagnostic yield and accuracy of $93.75 \%$ (15 of 16 patients) for US-guided core biopsy of osteolytic metastasis. Most of our cases were metastasis of adenocarcinomas (8 patients), squamous cell carcinomas ( 3 patients) followed by multiple myelomas ( 2 patients). Other pathologic lesions recorded were undifferentiated carcinoma (1 patient) and mesenchimal undifferentiated tumor (1 patient). The pathologic result was inconclusive in one patient. Conclusions: Our study supports the important diagnostic role of US-guided core biopsy for osteolytic bone metastasis. Two US-guided passages may be sufficient to procure a diagnostic tissue samples from osteolytic bone metastasis, if their length is at least $10 \mathrm{~mm}$.
\end{abstract}

Keywords: ultrasound-guided; bone metastasis; core biopsy

\section{Introduction}

The skeleton is one of the most common organs affected by metastatic cancer [1-3]. Breast and prostate cancers, followed by lung, thyroid and kidney cancers are the most common primary cancers associated with bone metastasis [3]. All this primary cancers may cause osteolytic lesions, but prostate cancer usually generates osteosclerotic lesions [4].

Received 20.09.2017 Accepted 22.10.2017

Med Ultrason

2018, Vol. 20, No 1, 50-56

Corresponding author: Romeo Ioan Chira, $\mathrm{MD}, \mathrm{PhD}$

1stInternal Medicine Department,

Gastroenterology Department

Emergency Clinical County Hospital Cluj

"Iuliu Hatieganu" University of Medicine and Pharmacy

3-5 Clinicilor str., 400006, Cluj-Napoca, Romania

Phone: 0040264592771/1172

E-mail: romeochira@yahoo.com
Bone biopsy is an essential tool for the diagnosis of neoplastic and infectious skeletal diseases $[5,6]$. In cases of malignant diseases, positive diagnosis is required in order to offer the best therapeutic strategy (e.g. resection, chemotherapy, radiotherapy). Percutaneous radiological guided bone biopsy is recognized now as a cost-effective and safe diagnostic procedure [7,8]. Even though open bone biopsy has an accuracy of $98 \%$, the procedure is also accompanied by complications in about $16 \%$ of the cases, including hematoma, infection, or tumor seeding [9]. On the other side, percutaneous computed tomography (CT) or ultrasound (US) guided needle biopsy has a reported diagnostic yield of 69-88\% [10-15] and an accuracy of $74-96 \%[6,8,10,12-25]$. It can be performed with aspiration or cutting needles, with some advantages for the latter, concerning the diagnostic yield and accuracy $[26,27]$. Other advantages are: lower costs for the percutaneous interventional procedures than for open surgical biopsies and also very low complication rates - of less than $1 \%[14,27]$. 
In experienced hands, US is able to detect or confirm bone enlargement or lytic lesions [28,29]. Osteolytic lesions can be caused by benign or malignant lesions. Paget disease or giant cell tumor are the most common benign causes, while metastases and multiple myeloma are the most frequent malignancies.

US is still underused in the diagnostic armamentarium of bone diseases and for guiding bone lesions biopsies, even though it is a cheaper, radiation-free and widely available imagistic method. Another advantage of US guidance is the possibility of real time monitoring of the needle during the procedure, providing a good/ perfect control of the procedure. Most of the radiological guided biopsies were performed under CT guidance, even though US can be used in many cases.

Many studies analyzed the role of percutaneous guided biopsy in bone tumors and the operators used most frequently radiological methods $[5,9]$. There are only a few studies of US guided biopsy of bone lesions [30-35]. A larger number of studies reported and analyzed CT and US-guided biopsies of bone together with soft tissue lesions, making the interpretation of the role of US guidance more difficult [27]. There are very few data concerning the use of US guided biopsy for the diagnosis of bone metastasis and the operators performed the procedures mostly with fine needle aspiration [36,37].

The purpose of this study was to analyze the diagnostic yield and accuracy of the US-guided bone core biopsy in a population of patients with osteolytic metastasis.

\section{Material and methods}

We performed a retrospective analysis of 16 consecutive cases of US-guided biopsies of osteolytic lesions performed in the Ultrasound Unit of the Gastroenterology Department of County Emergency Clinic Hospital, Cluj-Napoca. We included patients during the period January 2006- May 2017. Twelve patients (75\%) were males and the age was between 40-80 year old (mean age of 64.7).

Identification of bone lesions was done mostly on skeleton radiographs and CT scans. Eleven of 16 patients with bone metastasis were already diagnosed with various types of cancers or had a suspicion of a primary tumor site. Four were suspected for bone metastasis of unknown origin and presented osteolytic lesions. In two cases we discovered bone lesions with cortex disruption during performing US exam, guided by the local pain and/or tumefaction with recent onset. We performed ultrasound examinations with General Electric Logiq S6 ultrasound device with convex $2-6 \mathrm{MHz}$ and linear array 9-13 $\mathrm{MHz}$ transducers. After identification, osteolytic lesions were evaluated by US, in order to establish the feasibility of the US guided biopsy.

Patients with metastatic diseases do not have an indication for surgical treatment of the bone lesion. Biopsy tract resection should not be performed in order to avoid tumor seeding, as a preventive strategy [38].

According to our institutional Ethics Board, ethics approval is not required for retrospective studies. All patients signed informed consents for US-guided bone lesions biopsies at the time of the procedure.

\section{Biopsy procedure}

All US-guided biopsies were performed by the same consultant (RIC), with an experience of more than 15 years in interventional US. Radiological and US images were reviewed in order to choose the optimal approach. Vascular structures were also identified during US examination with color Doppler modes and avoided during the biopsies. All the procedures were performed on an inpatient basis, using only local anesthesia with lidocaine $1 \%$ (6-20 ml depending on the distance between the skin and target lesion). We used two types of biopsy guns: Bard ${ }^{\circledR}$ Biopty Gun ${ }^{\circledR}$ - with fixed $23 \mathrm{~mm}$ penetration depth and Bard ${ }^{\circledR}$ Magnum ${ }^{\circledR}$ with optional 15 or $22 \mathrm{~mm}$ penetration depth. Biopsies were performed with $18 \mathrm{G}$ or $16 \mathrm{G}$ Tru-cut needles, with free hand technique under US guidance. We used both convex and linear array transducers for biopsy guiding, depending on the depth and size of the bone lesions. We chose linear array transducer for clavicle tumors and convex array transducer for ribs, vertebrae, and sternal lesions. We performed ribs and clavicle located lesions biopsies in a plane almost parallel to the longitudinal axis of this bones. We also measured the tumor thickness on the anticipated needle tract, in order to avoid undesirable lung or other subjacent organ punctures.

One or two passages were performed until the tissue specimens (1-2 cores) were considered sufficient for histological examination. Rapid on sight evaluation (ROSE) was not available, therefore visual evaluation (length at least $10 \mathrm{~mm}$, solid consistency and whitish aspect) of the specimen by the interventionist was also noted and scored.

All patients underwent post-procedure surveillance on site for at least two hours.

Reference standard for final diagnosis was the histopathological examination.

We calculated the diagnostic yield as the number of biopsies that resulted in a diagnosis divided by the total number of biopsies performed. If the biopsy result confirmed the malignancy and the tumor type, we considered it to be accurate.

\section{Pathological analysis}

All tissue samples were analyzed by an experienced oncology pathologist. When considered necessary, the 
pathologist doctor had the possibility to compare the actual histopathology results with the previous ones, of the primary tumor.

\section{Results}

Demographic characteristics, information concerning primary tumor and results of the biopsies of the patients included in our study are presented in table I.

The maximum diameters of the lesions were $3.5-9 \mathrm{~cm}$ with an average of $5.2 \mathrm{~cm}$. We used $18 \mathrm{G}$ Tru-cut needles in 7 cases and $16 \mathrm{G}$ in 8 cases, and both types in one case.

In 12 cases we procured one core and in 4 cases we procured two cores, according to the visual characteristics of the specimens. If the first specimen was macroscopically unsatisfactory, we made the second biopsy.

Diagnostic yield of the osteolytic lesions biopsy in our series was $93.75 \%$, with an accuracy of $93.75 \%$ (15 of 16 cases) if we consider the only one inconclusive result.

There were no complications in our series of patients.

Metastases were recorded mostly in the axial skeleton. Most of the patients had rib lesions - 14 cases (fig 1 ), followed by vertebral lesions -8 cases (fig 2 ). In four patients we have detected both axial and appendicular skeleton metastasis. In one patient with the final pathological diagnosis of undifferentiated mesenchimal tumor with very aggressive evolution, we detected both appendicular skeleton metastasis - clavicle - which was most accessible for biopsy (fig 3) and axial metastasis (skull, vertebrae, ribs).

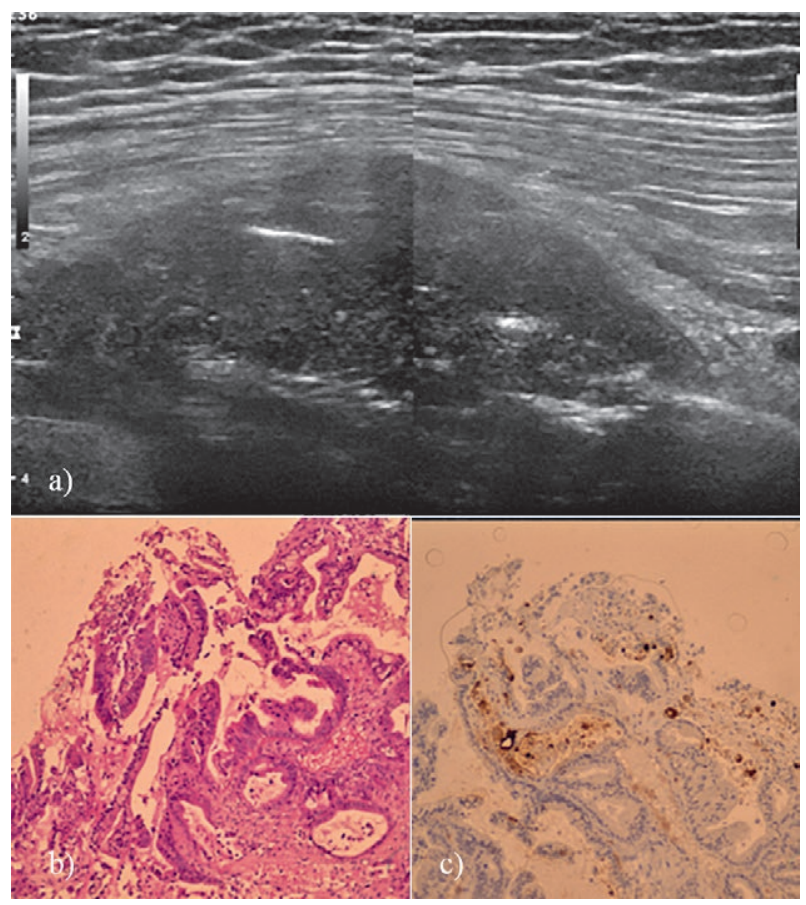

Fig 1. a) US image of a hypoechoic inhomogeneous ill-defined tumor originating in the $2^{\text {nd }}$ left rib, with large extraosseous component and hyperechoic bone fragments inside - osteolytic rib metastasis (pancreatic ductal carcinoma); b) Rib metastasis biopsy - epithelial tumoral proliferation with tubular structure, consistent with a malignant tumor with desmoplastic stroma (Hematoxylin-eosin 10x); c) immunohystochemistry - isolated positivity for CA 19-9 (and CK 7, CK 19, CEA, negative for TTF-1 and CK 20), consistent with pancreatic ductal carcinoma metastasis $(10 \mathrm{x})$.

Table I. Demographic characteristics, needle calibers used, cores characteristics, and results of the biopsies of the patients included in the study

\begin{tabular}{|c|c|c|c|c|c|c|c|c|c|}
\hline No. & Age & Sex & $\begin{array}{l}\text { Biopsy } \\
\text { site }\end{array}$ & $\begin{array}{l}\text { Max. di- } \\
\text { ameter* } \\
(\mathrm{cm})\end{array}$ & $\begin{array}{l}\text { Needle } \\
\text { caliber }\end{array}$ & $\begin{array}{l}\text { No. } \\
\text { of } \\
\text { cores }\end{array}$ & $\begin{array}{l}\text { Core } \\
\text { length } \\
(\mathrm{mm}) \\
\end{array}$ & Final histological result & Primary cancer site \\
\hline 1 & 56 & $\mathrm{M}$ & rib & 4.1 & $16 \mathrm{G}$ & 1 & 18 & multiple myeloma & \\
\hline 2 & 73 & M & rib & 7 & $18 \mathrm{G}$ & 1 & 16 & multiple myeloma & \\
\hline 3 & 66 & M & rib & 3.8 & $16 \mathrm{G}$ & 1 & 19 & squamous cell carcinoma (SQC) & pharynx (SQC) \\
\hline 4 & 64 & M & rib & 3.5 & $16 \mathrm{G}$ & 1 & 14 & lung - adenocarcinoma & lung \\
\hline 5 & 67 & M & vertebrae & 4 & $18 \mathrm{G}$ & 2 & 20 & squamous cell carcinoma & larynx (SQC) \\
\hline 6 & 63 & M & rib & 6 & $18 \mathrm{G}$ & 1 & 15 & lung adenocarcinoma & lung \\
\hline 7 & 71 & M & rib & 4 & $18 \mathrm{G}$ & 1 & 15 & undifferentiated carcinoma & unknown \\
\hline 8 & 59 & M & rib & 3.8 & $16 \mathrm{G}$ & 1 & 13 & pancreatic ductal carcinomtya & pancreatic \\
\hline 9 & 68 & M & rib & 6 & $16 \mathrm{G}$ & 1 & 16 & prostatic adenocarcinoma & prostate \\
\hline 10 & 66 & $\mathrm{M}$ & $\mathrm{rib}$ & 4.2 & $16 \mathrm{G}$ & 2 & 20 & renal carcinoma & renal \\
\hline 11 & 80 & M & sternum & 9 & $18 \mathrm{G}$ & 1 & 15 & hepatocellular carcinoma & hepatocellular carcinoma \\
\hline 12 & 72 & $\mathrm{~F}$ & rib & 7 & $18 \mathrm{G}$ & 2 & 18 & lung - adenocarcinoma & lung \\
\hline 13 & 72 & $\mathrm{~F}$ & $\mathrm{rib}$ & 4.2 & $18 \mathrm{G}$ & 1 & 15 & adenocarcinoma - undifferentiated & unknown \\
\hline 14 & 40 & $\mathrm{~F}$ & clavicle & 5.7 & $18 \mathrm{G}$ & 1 & 14 & mesechimal tumor - undifferentiated & rectal and endometrial \\
\hline 15 & 59 & M & $\mathrm{rib}$ & 6.1 & $16 \mathrm{G}$ & 1 & 13 & lung - squamous cell carcinoma & lung (SQC) \\
\hline 16 & 60 & $\mathrm{~F}$ & sacrum & 3.5 & $18 \mathrm{G}+16 \mathrm{G}$ & 2 & 6 & inconclusive (non-malignant) & breast adenocarcinoma \\
\hline
\end{tabular}

*Maximum diameter of the lesion; SQC - squamous cell carcinoma 


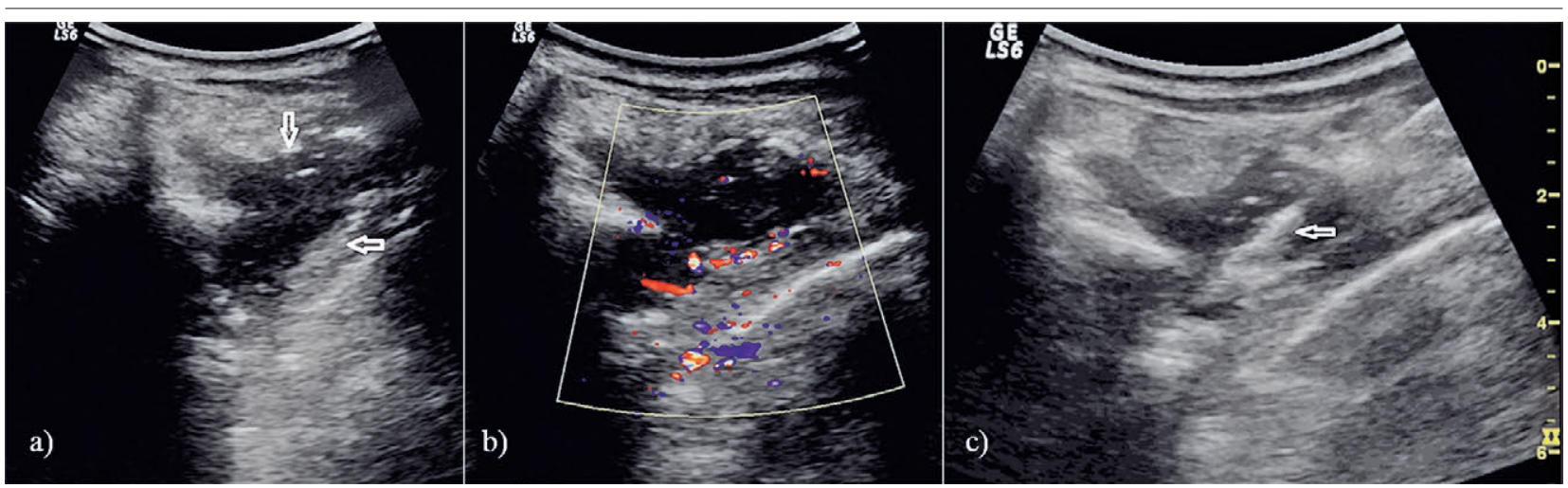

Fig 2. a) Osteolytic metastasis of the right transvers process of a dorsal vertebrae - irregular ill-defined hypoechoic mass invading paravertebral space (arrows); b) color Doppler examination of the vertebral metastases showing presence of vessels inside the tumor during the pre-bioptic evaluation; c) hyperechoic biopsy needle inside the vertebral metastases (arrow).

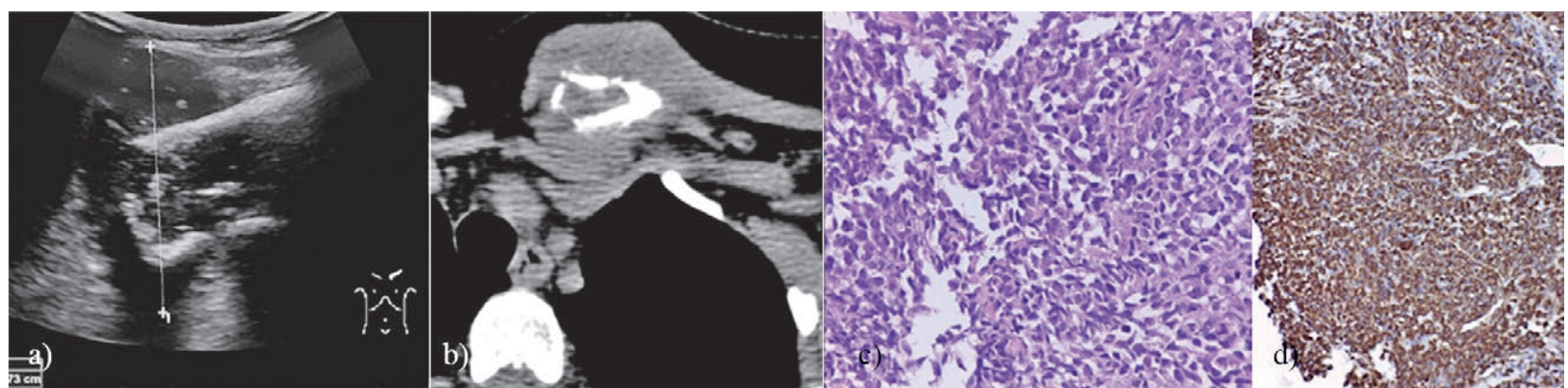

Fig 3. a) US image of a large hypoechoic osteolytic tumor located to the medial epiphysis of the left clavicle, with large extraosseous component; b) CT image of the left clavicle osteolytic tumor enlarging the medial epiphysis contour; c) pathological aspect - malignant proliferation of small and medium sized cells with clear cytoplasm, round/oval shaped hyper chromatic nuclei corresponding to a mesenchimal undifferentiated metastasis (haematoxilin-eosin 10x); d) immunohistochemical aspect - vimentin positive cells in mesenchimal undifferentiated clavicle metastases (10x).

The results of the pathological examination are detailed in table I. We encountered also unusual cases of bone metastasis (pancreatic adenocarcinoma, hepatocellular carcinoma) (Table I, cases no. 8, 11). In three cases $(18.75 \%)$ metastatic cancer was confirmed, but without identification of a primary site (Table I, cases no. 7, 13, 14). In a patient with breast cancer diagnosed 7 years before and a sacral lesion suggestive for metastasis, we could not obtain enough metastatic tissue and the pathological result was inconclusive (Table I, case no. 16).

\section{Discussions}

It is known that breast, prostate, kidney, and lung cancers cause three out of four cases of bone metastasis [39]. Also in advanced breast and prostate cancers the bone may be the first metastatic site and approximately $70 \%$ of the patients dying of this diseases had evidence of bone metastasis at autopsy [3]. Osteolytic lesions are commonly encountered in breast, lung, kidney, ovarian, and pancreatic carcinomas as well as in multiple myelo- ma [40]. A particular clinical situation is the appearance of a bone lesions suspected to be metastasis after more than 5 years after a confirmed cancer or with an occult primary cancer.

Modern imaging modalities can detect and characterize bone lesions and raise the suspicion of metastasis and histological diagnosis is a prerequisite for an optimal treatment. There are many studies concerning image guided musculoskeletal biopsies performed with radiological methods - mostly CT, but only few studies analyzed US-guided biopsies [studies cited by 27]. There is a limited number of studies regarding US-guided bone lesions biopsies. They included usually small populations of patients, some with tumors invading the bones [41]. In this study we excluded the intrathoracic tumors which can invade the bony parts of the thorax.

In our study US percutaneous guided biopsy provided the diagnosis of malignancy in 15 of 16 cases $(93.75 \%)$, recommending it as a successful alternative to $\mathrm{CT}$ guidance, as found by other authors [2]. Moreover, it allowed the confirmation of the cancer type in 15 of 16 patients. In 
three cases, histopathology results recorded undifferentiated carcinoma, undifferentiated adenocarcinoma, and undifferentiated mesenchimal tumor metastasis, without the identification of a primary tumor (cases no. 7,13,14, Table I). Those three patients died within 3 to 5 months after the diagnosis, showing a very short survival time as compared to breast or prostate bone metastasis which are associated with median survival of 24 to 40 months [1]. A particular aspect is patient no. 14 with undifferentiated mesenchimal metastasis who had been previously diagnosed with two other cancers - rectal (stage pT2N0Mx, G1) four years before and endometrioid endometrial cancer (stage $\mathrm{pT}(\mathrm{m}) 1 \mathrm{aNxMx}$, FIGO 1) one year before we diagnosed this third, very aggressive metastatic malignancy. This case supports the need of confirmation of the pathological type of bone metastasis in situations of multiple primary cancers.

US examination allows the identification of the soft part of a bone lesion. In our study we targeted the extraosseous components of the osteolytic metastasis when it was larger than $5 \mathrm{~mm}$ or we biopsied the hypoechoic masses arising from the bones, avoiding the hyperechoic bone fragments included. When the bone lesion is not lytic or is sclerotic, other guiding methods (CT) or open biopsy are preferred.

One of the main issues of percutaneous guided biopsy is the relative small amount of the tissue sample obtained. Sometimes it is insufficient for multiple histopathology and immunohistochemical staining required in cases of primary bone tumors, which can be heterogeneous. Using large caliber needles (14-16G), specialized types of needles (Ostycut $\AA$, Bonopty $\AA$, etc), and multiple passages can overcome this problem. The medium number of passages or cores recommended to be procured during image-guided bone lesions biopsy is 3 [15,27]. In recent studies, the operators also obtained only 2 cores with good accuracy for histopathology diagnosis [42]. In our study we used 18 or $16 \mathrm{G}$ Tru-cut needles coupled with biopsy guns. We chose to evaluate visually the tissue specimen and procure 1-2 cores, considering bone metastasis less histologically heterogeneous than primary bone tumors. In this setting we achieved a very good diagnostic yield. Other authors found that tissue specimens longer than $10 \mathrm{~mm}$ provided $82 \%$ diagnostic yield [15]. We used this information when we decided to procure less cores, but of good quality, macroscopically evaluated. In 15 of our 16 cases we procured visually satisfactory specimens, longer than $10 \mathrm{~mm}$, performing only one or two biopsies. If the first specimen was macroscopically unsatisfactory (in 4 cases) we made the second passage, obtaining better specimens (according to our criteria) in another 3 cases. Needle tract seeding was mentioned af- ter core biopsy, mostly in primary bone tumors (i.e. osteosarcoma) $[43,44]$ but is not a prognostic factor in bone metastasis.

Our study included a relatively small number of patients. We had four types of clinical scenarios with osteolytic lesions in our patients: late onset (more than 5 years) of osteolytic lesions suspected of metastasis after being diagnosed with cancer, unknown or unconfirmed primary cancer, multiple myeloma patients and patients with multiple primary cancers. Even though our case series is restrained, we encountered also bone metastasis secondary to squamous cell cancer of pharynx and larynx origin, pancreatic carcinoma and hepatocellular carcinoma, which are statistically less common. Our series of patients with bone metastasis cannot be compared with studies concerning the prevalence of bone metastasis in certain types of cancers, since these patients are selected from patients referred for a US-guided biopsy. We did not exclude from our study multiple myelomas, even though it is a primary bone tumor, usually multicentric, because its clinical and imagistic behavior was metastatic-like in our cases.

Even though our study goes back in time to year 2006, the majority of biopsies were performed in the last years. In the period January 2015-May 2017 we performed 11 of our 16 biopsies, illustrating the rising need for this kind of diagnostic procedure in the last three years and the availability of a dedicated operator and techniques. Another interesting aspect and limiting factor is the lack of knowledge concerning this medical procedure among medical professionals, which seemed to improve over the time after dissemination of information.

We consider that percutaneous US-guided biopsy of suspected bone metastatic lytic lesions could offer a good alternative for the diagnosis and the management in individual patient's approach. It can avoid CT guided biopsy - with higher costs, ionizing radiation exposure, longer time and other disadvantages, and open biopsy with more complications, higher costs and greater strains on patients. US-guided bone lesions biopsy is a procedure with proven efficacy. Further studies are required, in order to establish the role and the place of US-guided biopsy, in comparison to other modalities used for the same diagnostic purpose, of obtaining a diagnostic specimen in metastatic lytic lesions.

\section{Conclusions}

Our study supports the diagnostic role of US-guided bone core biopsy for osteolytic metastasis, competing with the classical methods. Due to its high diagnostic yield and accuracy, we would propose to start the inva- 
sive diagnostic algorithm of osteolytic lesions, suspected as metastases, with the US-guided biopsy approach. In our experience, the number of the biopsy cores procured might be smaller - respectively two, when the quantity (biopsy specimen of at least $10 \mathrm{~mm}$ in length) and the quality of the tissue specimen is macroscopically appropriate.

\section{Conflict of interest: none}

\section{References}

1. Coleman RE. Skeletal complications of malignancy. Cancer1997;80:1588-1594.

2. Rubens DJ, Fultz PJ, Gottlieb RH, Rubin SJ. Effective ultrasonographically guided intervention for diagnosis of musculoskeletal lesions. J Ultrasound Med1997;16:831842.

3. Galasko CSB. Incidence and distribution of skeletal metastases. In: Galasko CSB (eds). Skeletal Metastases. London: Butterworth; 1986:14-21.

4. Guise TA, Mundy GR. Cancer and bone. Endocr Rev1998;19:18-54.

5. Ogilvie CM, Torbert JT, Finstein JL, Fox EJ, Lackman RD. Clinical utility of percutaneous biopsies of musculoskeletal tumors. Clin Orthop Relat Res 2006;450:95-100.

6. Mitsuyoshi G, Naito N, Kawai A, et al. Accurate diagnosis of musculoskeletal lesions by core needle biopsy. J Surg Oncol 2006;94:21-27.

7. Kattapuram SV, Rosenthal DI. Percutaneous biopsy of skeletal lesions. AJR Am J Roentgenol 1991;157:935-942.

8. Fraser-Hill MA, Renfrew DL. Percutaneous needle biopsy of musculoskeletal lesions. 1. Effective accuracy and diagnostic utility. AJR Am J Roentgenol 1992;158:809-812.

9. den Heeten GJ, Oldhoff J, Oosterhuis JW, Schraffordt Koops H. Biopsy of bone tumours. J Surg Oncol 1985;28:247251.

10. Datir A, Pechon P, Saifuddin A. Imaging-guided percutaneous biopsy of pathologic fractures: a retrospective analysis of 129 cases. AJR Am J Roentgenol 2009;193:504-508.

11. Harish S, Hughes RJ, Saifuddin A, Flanagan AM. Image-guided percutaneous biopsy of intramedullary lytic bone lesions: utility of aspirated blood clots. Eur Radiol 2006;16:2120-2125.

12. Ng CS, Salisbury JR, Darby AJ, Gishen P. Radiologically guided bone biopsy: results of 502 biopsies. Cardiovasc Intervent Radiol 1998;21:122-128.

13. Puri A, Shingade VU, Agarwal MG, et al. CT-guided percutaneous core needle biopsy in deep seated musculoskeletal lesions: a prospective study of 128 cases. Skeletal Radiol 2006;35:138-143.

14. Welker JA, Henshaw RM, Jelinek J, Shmookler BM, Malawer MM. The percutaneous needle biopsy is safe and recommended in the diagnosis of musculoskeletal masses. Cancer 2000;89:2677-2686.
15. Wu JS, Goldsmith JD, Horwich PJ, Shetty SK, Hochman MG. Bone and soft-tissue lesions: what factors affect diagnostic yield of image-guided core-needle biopsy? Radiology 2008;248:962-970.

16. Altuntas AO, Slavin J, Smith PJ, et al. Accuracy of computed tomography guided core needle biopsy of musculoskeletal tumours. ANZ J Surg 2005;75:187-191.

17. Ayala AG, Zornosa J. Primary bone tumors: percutaneous needle biopsy. Radiologic-pathologic study of 222 biopsies. Radiology 1983;149:675-679.

18. Dupuy DE, Rosenberg AE, Punyaratabandhu T, Tan $\mathrm{MH}$, Mankin HJ. Accuracy of CT-guided needle biopsy of musculoskeletal neoplasms. AJR Am J Roentgenol 1998;171:759-762.

19. Hau A, Kim I, Kattapuram S, et al. Accuracy of CT-guided biopsies in 359 patients with musculoskeletal lesions. Skeletal Radiol 2002;31:349-353.

20. Issakov J, Flusser G, Kollender Y, Merimsky O, LifschitzMercer B, Meller I. Computed tomography-guided core needle biopsy for bone and soft tissue tumors. Isr Med Assoc J 2003;5:28-30.

21. Logan PM, Connell DG, O’Connell JX, Munk PL, Janzen DL. Image-guided percutaneous biopsy of musculoskeletal tumors: an algorithm for selection of specific biopsy techniques. AJR Am J Roentgenol 1996;166:137-141.

22. Skrzynski MC, Biermann JS, Montag A, Simon MA. Diagnostic accuracy and charge-savings of outpatient core needle biopsy compared with open biopsy of musculoskeletal tumors. J Bone Joint Surg Am 1996;78:644-649.

23. Tsukushi S, Katagiri H, Nakashima H, Shido Y, Arai E. Application and utility of computed tomography-guided needle biopsy with musculoskeletal lesions. J Orthop Sci 2004;9:122-125.

24. Tsukushi S, Nishida Y, Yamada Y, Yoshida M, Ishiguro N. CT-guided needle biopsy for musculoskeletal lesions. Arch Orthop Trauma Surg 2010;130:699-703.

25. Yao L, Nelson SD, Seeger LL, Eckardt JJ, Eilber FR. Primary musculoskeletal neoplasms: effectiveness of coreneedle biopsy. Radiology 1999;212:682-686.

26. Gil-Sanchez S, Marco-Domenech SF, Irurzun-Lopez J, Fernandez-Garcia P, de la Iglesia-Cardena P, Ambit-Capdevila S. Ultrasound-guided skeletal biopsies. Skeletal Radiol 2001;30:615-619.

27. Chira RI, Chira A, Manzat-Saplacan RM, et al. Ultrasoundguided bone lesions biopsies - a systematic review. Med Ultrason 2017;19:302-309.

28. Sarazin L, Bonaldi VM, Papadatos D, Chhem RK. Correlative imaging and pattern approach in ultrasonography of bone lesions: a pictorial essay. Can Assoc Radiol J 1996;47:423-430.

29. Saifuddin A, Burnett SJ, Mitchell R. Pictorial review: ultrasonography of primary bone tumours. Clin Radiol 1998;53:239-246.

30. Bazzocchi M, Gozzi G, Zuiani C, Pozzi Mucelli RS. Ultrasonic-guided fine-needle biopsy of osteolytic lesions. Radiol Med 1988;76:23-27. 
31. Hsu WH, Chiang CD, Hsu JY, Huang WL. Impalpable thoracic bony lesions diagnosed by sonographically guided needle aspiration biopsy. J Ultrasound Med 1992;11:105-109.

32. Gupta RK, Gupta S, Tandon P, Chhabra DK. Ultrasoundguided needle biopsy of lytic lesions of the cervical spine. J Clin Ultrasound 1993;21:194-197.

33. Gupta S, Takhtani D, Gulati M, et al. Sonographically guided fine-needle aspiration biopsy of lytic lesions of the spine: technique and indications. J Clin Ultrasound 1999;27:123-129.

34. Saifuddin A, Mitchell R, Burnett SJ, Sandison A, Pringle JA. Ultrasound-guided needle biopsy of primary bone tumours. J Bone Joint Surg Br 2000;82:50-54.

35. Ahrar K, Himmerich JU, Herzog CE, et al. Percutaneous ultrasound-guided biopsy in the definitive diagnosis of osteosarcoma. J Vasc Interv Radiol 2004;15:1329-1333.

36. Civardi G, Livraghi T, Colombo P, Fornari F, Cavanna L, Buscarini L. Lytic bone lesions suspected for metastasis: ultrasonically guided fine-needle aspiration biopsy. J Clin Ultrasound 1994;22:307-311.

37. Shergill U, Vitkovski T, Stoffels G, et al. Fine-needle aspiration biopsy of lytic bone lesions: An institution's experience. Diagn Cytopathol 2017;45:989-997.
38. Liu PT, Valadez SD, Chivers FS, Roberts CC, Beauchamp CP. Anatomically based guidelines for core needle biopsy of bone tumors: implications for limb-sparing surgery. Radiographics 2007;27:189-205; discussion 206.

39. Rubens RD. The nature of metastatic bone disease. In: Rubens RD, Fogelman IE, editors. Bone Metastases - Diagnosis and Treatment. London: Springer-Verlag; 1991:110.

40. Mundy GR. Metastasis to bone: causes, consequences and therapeutic opportunities. Nat Rev Cancer 2002;2:584-593.

41. Targhetta R, Balmes P, Marty-Double C, Mauboussin JM, Bourgeois JM, Pourcelot L. Ultrasonically guided aspiration biopsy in osteolytic bone lesions of the chest wall. Chest 1993;103:1403-1408.

42. Govindan NO, Prasanth J, Gopakumar TS, et al. A study on core cut biopsy in bone lesions. Int J Orthod Sci 2017;3:913.

43. Schwartz HS, Spengler DM. Needle tract recurrences after closed biopsy for sarcoma: three cases and review of the literature. Ann Surg Oncol 1997;4:228-236.

44. Davies NM, Livesley PJ, Cannon SR. Recurrence of an osteosarcoma in a needle biopsy track. J Bone Joint Surg Br 1993;75:977-978. 